\title{
Application of the MM5 and the analogous method to heavy rainfall event, the case of 16-18 October 2003 in Catalonia (NE Spain)
}

\author{
V. Altava-Ortiz ${ }^{1}$, A. Barrera ${ }^{1}$, M. C. Llasat ${ }^{1}$, M. A. Prat ${ }^{1}$, J. Gibergans-Báguena ${ }^{2}$, and M. Barnolas ${ }^{1}$ \\ ${ }^{1}$ Meteorological Hazards Analysis Team (GAMA), Department of Astronomy \& Meteorology, Faculty of Physics. University \\ of Barcelona, Av. Diagonal 647, E-08028 Barcelona, Spain \\ ${ }^{2}$ Department of Applied Mathematics III, EUETIB, Politechnical University of Catalonia, C. Comte d'Urgell 187, E-08036 \\ Barcelona, Spain
}

Received: 8 October 2005 - Revised: 23 January 2006 - Accepted: 20 February 2006 - Published: 21 April 2006

\begin{abstract}
Between the 16 and 18 October 2003, some amounts of precipitation greater than $225 \mathrm{~mm}$ and sea waves higher than $8.5 \mathrm{~m}$ were recorded in Catalonia (NE Spain) and near its coast. Some rivers in the NE of the region were overflowed and the sea swell produced several damages near the coast. In order to analyse this case and to improve the forecasting of events like this, two methodologies have been applied: one deterministic and another one, probabilistic. The deterministic analysis has been made by using the MM5 mesoscale model. A $48 \mathrm{~h}$ simulation has been designed for three domains connected with two way nesting and having $54,18,6 \mathrm{~km}$ horizontal grid resolution and vertical resolution of 23 levels, and it has been initialised with the NCEP Analyses. The simulation suggests that orography played an important role on the precipitation generation (maxima were located where the wind at low levels impinged on the mountain ranges perpendicularly). The strong pressure gradient produced in the North of Catalonia and West part of the Gulf of Lyon, was the responsible of the great marine alteration. On the other hand, the $6 \mathrm{~km}$ resolution precipitation forecast for Catalonia is accurate, since it shows a spatial distribution and amounts quite similar to the observations obtained from 315 automatic rain gauges. The analogous technique applied here, considers the meteorological situations similar to the current one, in terms of the 850 and $1000 \mathrm{hPa}$ geopotential fields at 00:00 UTC and 12:00 UTC from the NCEP/NCAR meteorological reanalysis for the period 1958-2003. Two windows have been considered, the first one from $60^{\circ} \mathrm{N}$ to $30^{\circ} \mathrm{N}$ and from $30^{\circ} \mathrm{W}$ to $30^{\circ} \mathrm{E}$, and the second one, centred in Catalonia, from $45^{\circ} \mathrm{N}$ to $37.5^{\circ} \mathrm{N}$ and from $5^{\circ} \mathrm{W}$ to $10^{\circ} \mathrm{E}$. The best 100 analogous have been selected and the comparison of the results with those obtained for other heavy rainfall events has been also done.
\end{abstract}

Correspondence to: V. Altava-Ortiz

(valtava@am.ub.es)

\section{Introduction}

Heavy rainfall events produce the majority of the natural damages registered in Catalonia (NE of Spain). For instance, the most important events in the last five years were 9-10 June 2000 (Llasat et al., 2003), 21-24 October 2000 (Barnolas, 2004), 8-9 October 2002 (Llasat et al., 2004a) and 16-18 October 2003, and they gave place to more than EUR 150000000 and 11 deaths. This figure is important if we consider that only the events recorded on the year 2000 were catastrophic (Llasat et al., 2006). Those damages are related with the strong risk of floods that characterises part of the region. More than five million persons live in the coast strip, a flood-prone area. This fact, joined to several facts such as holes in legislation, emergence procedures or high pressure over the territory produces a strong vulnerability and, joined to the high frequency of heavy rainfalls and the geomorphologic features drives to a high flood risk. Fortunately, nowadays that is being taking into account and some directives have appeared from European and national institutions (Llasat, 2004b).

In the last years, more available meteorological data and technical advances have made possible the study of a particular case from different points of view. For instance, great advances have appeared in radar analysis and second generation satellites with more detailed information allowing to improve the nowcasting. On the other hand, mesoscale models, such as MM5, joined with other techniques like analogous techniques make possible to study a meteorological event from different points of view at larger time scales.

The Analogous method was developed during 1970's by Duband $(1970,1974,1981)$ in order to address the concerns of Électricité de France's (EDF, Electricity of France) Hydraulic Production and Energy Flows departments. This method is based on the assumption that values of different meteorological variables observed in a certain meteorological context, could be observed again if this meteorological 


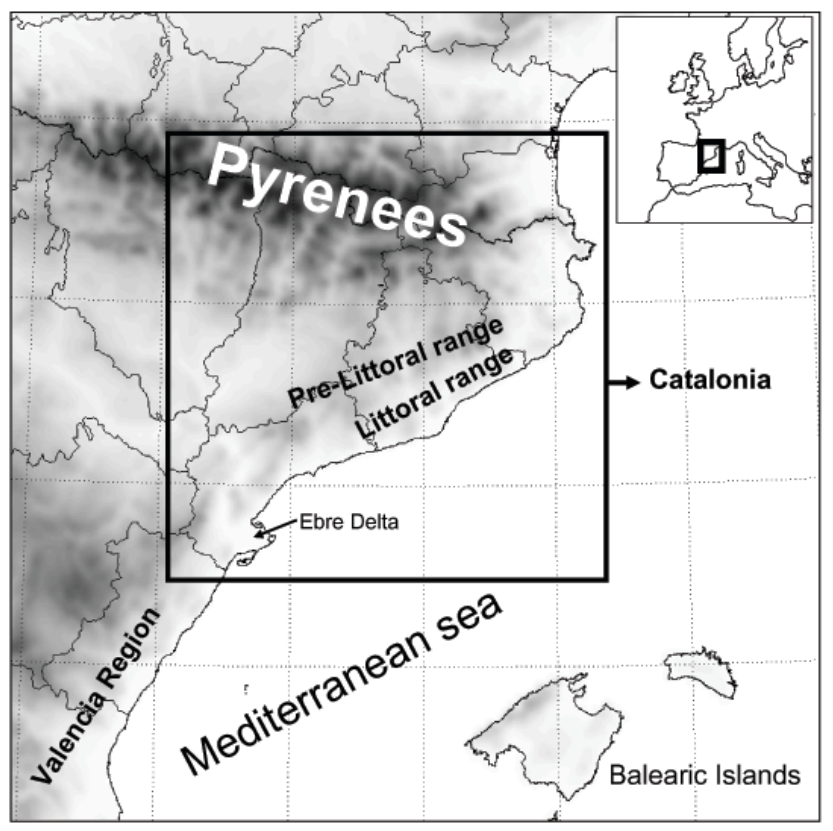

Fig. 1. Main orographic systems of Catalonia (NE Spain) and locations mentioned within the text.

context was repeated. This fact can be used for forecasting meteorological events. Afterwards, different works from the analogous point of view have been developed (Guilbaud, 1997; Gibergans-Báguena, 2001; Obled et al., 2003; Bontron, 2004).

On the other hand, the MM5 meteorological mesoscale model has demonstrated to be suitable in rainfall distribution simulation on different study cases in Mediterranean region (Mariani et al., 2005; Romero et al., 2005) as it will be shown.

In this article both techniques, MM5 mesoscale model and Analogous method, are applied to 16-18 October 2003 case, which affects all Mediterranean Spanish coast, specially the North-East of Catalonia. Their individual results are discussed as well as compared.

\section{Study area and event overview}

Catalonia has a complex orography that has a great influence on pluviometry, producing strong contrasts in few kilometres. Over all, it can be mentioned three orographic systems (Fig. 1). First of all, the Pyrenees in the north that rises over $3000 \mathrm{~m}$. The second one is the Littoral range that goes parallel along the coast line and rises more than $700 \mathrm{~m}$. Finally the Pre-littoral system has maxima altitudes between 1000 and $1700 \mathrm{~m}$. This orography has an important role on high rainfall production (Llasat et al., 1999). Particularly, in this case the most important contribution was due to the eastern parts of the Pyrenees and the Pre-Littoral range.

On 15 October 2003 a depression was configuring over Portugal at $500 \mathrm{hPa}$ that following days, moved to the Gibraltar strait. At the same time a low pressure centre was forming

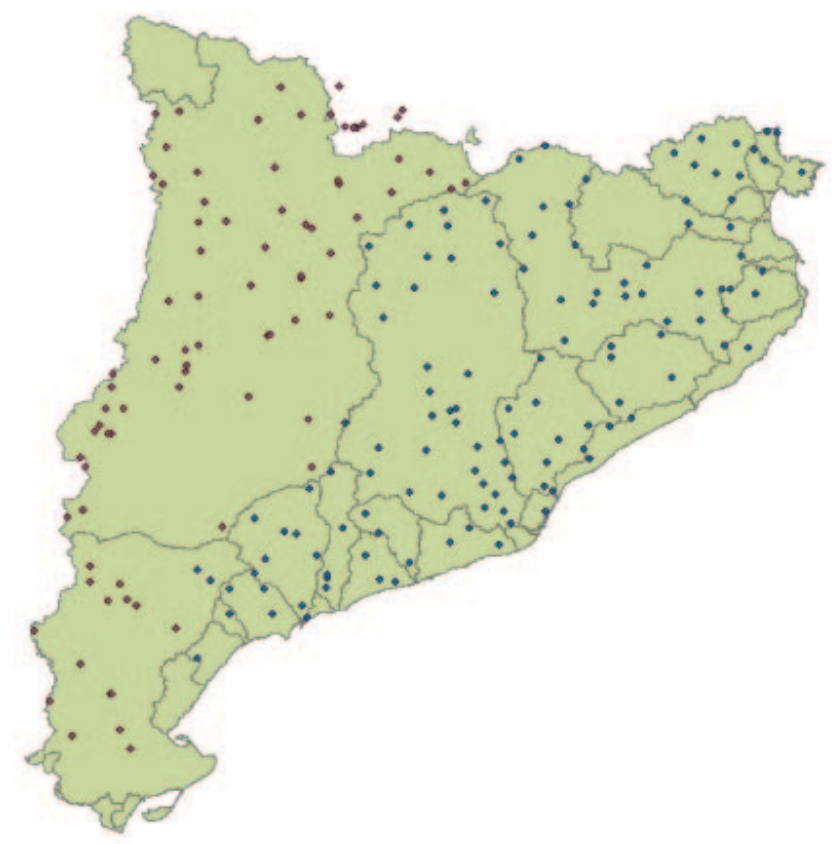

Fig. 2. Stations with available pluviometric data. Blue ones are involved into the analogous process selection.

over the Balearic Islands, which on 16 was located in front of the Catalan coast. More than $225 \mathrm{~mm}$ in $48 \mathrm{~h}$ (maximum accumulated precipitation in $48 \mathrm{~h}$ of $231.8 \mathrm{~mm}$ ) were recorded in some places and wind speed was also remarkable, with speeds higher than $100 \mathrm{~km} / \mathrm{h}$ that produced a lot of damages. A strong sea temporal affected the coast, with waves between 3 and $4 \mathrm{~m}$ in the central Catalan coast and $7 \mathrm{~m}$ or even more near the north one. The heavy rainfalls and the sea swell produced some floods in the North coastal region. The severe weather, unfortunately, also caused one death.

\section{Data and methodology}

Two different methodologies have been used to study the event: a deterministic method, using the MM5 model, and other probabilistic one: the analogous method. Both methods have been applied separately and a comparison between them has been made.

\subsection{Meteorological data for Analogous method}

The analogous method works using a $2.5^{\circ}$ gridded pressure database at 1000, 850 and $500 \mathrm{hPa}$ levels. The values used in this work begin on 1 January 1958 and finish on 31 December 2004 and are available at 00 and 12:00 UTC. The pressure data values are provided by the NCEP-NCAR Reanalysis Project (NNRP). The procedure followed and introduced at the present work, was validated using daily rainfall data for the period 1970-1983 (Gibergans-Báguena, 2001), wich was carried out taking into account 53 stations covering Catalonia. On the other side, values of probability rainfall are 
obtained from the SAIH rain gauge data base (1996-2004). This database has much more resolution than the used one into the validation process. Thus, an excellent cover over East Catalonia (Fig. 2) with more than 120 stations for an area of $16000 \mathrm{~km}^{2}$ can be performed. Similar periods but with not so good station density has been developed by other institutions for operational forecasts: Spain (10 years, Del Hoyo et al., 2000) and Italy (14 years, Diomede, 2003).

Into the analogous process two domains are involved: Domain 1, which is the First Selection Window (FSW) and is delimited from $60^{\circ} \mathrm{N}$ to $30^{\circ} \mathrm{N}$ and from $30^{\circ} \mathrm{W}$ to $30^{\circ} \mathrm{E}$ and has a $2.5^{\circ}$ grid resolution. This first domain is useful to look for an analogous situation from a synoptic point of view. Due to the fact that heavy rainfall in Catalonia is usually produced by mesoscale processes (Ramis et al., 1994; Mariani et al., 2005; Zampieri et al., 2005), it would be need to select those days that would have a similar meteorological situation around Catalonia. To get this purpose, a Domain 2 has been made. This domain is the Second Selection Window (SSW) and is centred in Catalonia. It is delimited from $37.5^{\circ} \mathrm{N}$ to $45^{\circ} \mathrm{N}$ and from $5^{\circ} \mathrm{W}$ to $10^{\circ} \mathrm{E}$ (Fig. 3).

\subsection{The probabilistic model: the Analogous Method}

As explained above, the analogous method takes into account the weather observed in the past associated to certain meteorological contexts. When a meteorological situation is forecasted and applying some similarity criteria, several past situations are selected. Two atmospheric states are deemed "analogous" when there is certain resemblance between them (Lorentz, 1969). After that, the model outputs are calculated using the meteorological observations corresponding to selected situations. Different criteria to consider two states as analogous can be applied in addition to different variables to do the selection.

At the present work, two selection criteria take part in the selection of "analogous situations". The first one is a "criterion of proximity" in a space of $n$ dimensions ( $n$ is related with the number of freedom degrees). The second one is a "criterion of correlation" between variables that characterise an atmospheric state. Only the states that have parameters higher than a prefixed threshold are selected as analogous.

The "criterion of proximity" takes into account geopotential values at 1000 and $850 \mathrm{hPa}$ levels which describe the meteorological state of the atmosphere. As said above, the FSW is an extense area and represents a considerate number of points where data is available. This fact is an advantage in atmosphere description, but on the other hand, it holds a trouble due to the great number of freedom degrees, falling down the process. To decrease the number of freedom degrees, but trying to maintain a good system description, an EOF process has been developed. The first six Principal Components (PC) keep near $80 \%$ of system variance, which is accepted as a reasonable level. Taking each PC as independent from the others, the space which represents the considered meteorological state has six dimensions.

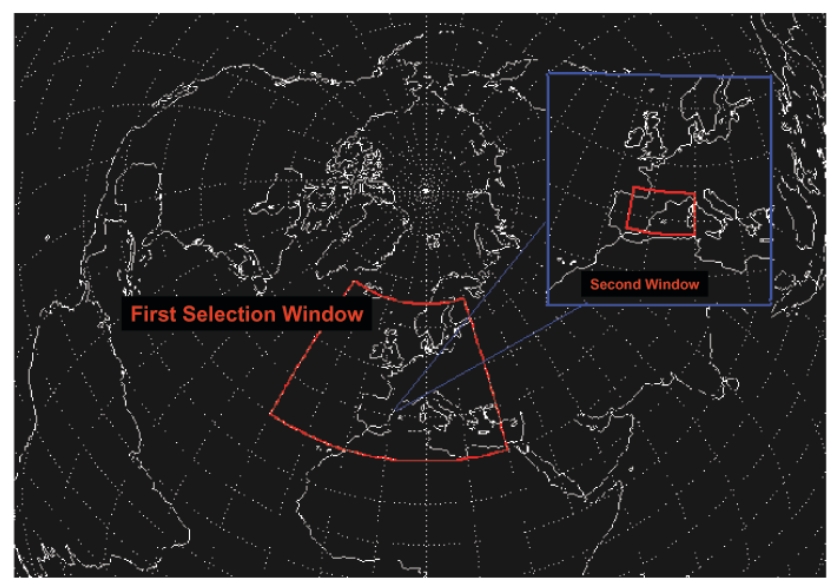

Fig. 3. Different domains used in analogous technique.

The considered analogous situations are those that lie in the interior of a six-ball of radius $d$ in a 6-dimensional space. The radius is taken as a function of the distance, $d$, to the origin of the test day, $t$, as a follows:

$\sum_{j=1}^{N}\left(Z_{i j}-Z_{t j}\right)^{2}<d^{2}$

where $Z_{i j}$ is the value of the variable $Z_{j}$ on the day $i$, and $Z_{t j}$ is the variable value on the forecasted day (test day). To calculate the distance " $d$ " the procedure is as follows. Let $D$ be the distance to the origin of the test day, so that:

$D^{2}=\sum_{i=1}^{N}\left(Z_{i}\right)^{2}$

The variable $D^{2}$ follows a $\chi^{2}$ distribution law with $N$ degrees of freedom, since $Z_{1}, Z_{2}, Z_{N}$ are considered independent and identically distributed. For a law of $\chi^{2}$ with $N$ degrees of freedom, the function of density is given by the expression:

$f(x)=\frac{x^{(n / 2)-1} e^{-x / 2}}{2^{n / 2} \Gamma\left(\frac{n}{2}\right)}, \quad$ with $\quad \Gamma(n)=(n-1)$ !

As the first six PC have been retained, the density function takes the next form:

$f(x)=\frac{x^{2} e^{-x / 2}}{16}$

that corresponds to a Gamma function with parameters $(\lambda=3$ and $\rho=2$ ). Any quartile of this function of density has a typical deviation $\sigma_{D}$ proportional to the size of the sample, $m$, that is, to the number of analogous situations for each test day. If 25 analogous days are considered then:

$\sigma_{D}=\frac{1}{f(x)} \sqrt{\frac{p(1-p)}{m}}=\frac{1}{f(x)} \sqrt{\frac{p(1-p)}{25}}$

in which, $p$ is the probability calculated by interpolation based on a table of the Gamma distribution with six degrees of freedom. 
Table 1. Probability thresholds and outputs of the analogous technique.

\begin{tabular}{ll}
\hline ERP(0.5) & Expected Rainfall Probability $>0.5 \mathrm{~mm} /$ day \\
ERP(2) & Expected Rainfall Probability $>2 \mathrm{~mm} /$ day \\
ERP(10) & Expected Rainfall Probability $>10 \mathrm{~mm} /$ day \\
ERP(20) & Expected Rainfall Probability $>20 \mathrm{~mm} /$ day \\
ERP(50) & Expected Rainfall Probability $>50 \mathrm{~mm} /$ day \\
MER & Maximum Expected Rainfall $/$ day \\
AER & Average Expected Rainfall
\end{tabular}

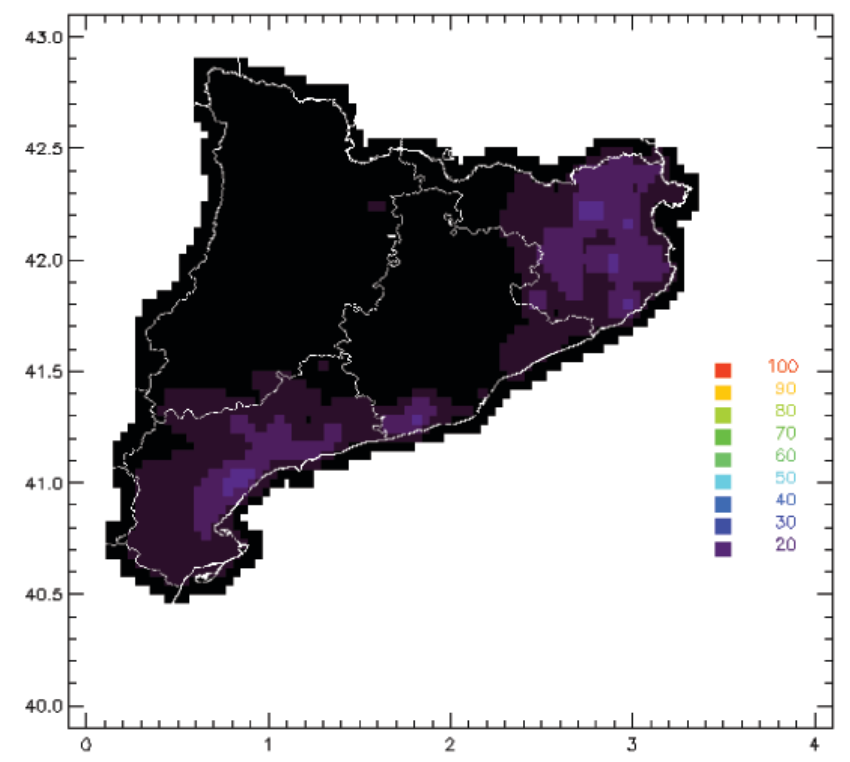

Fig. 4. MER (>20 mm/day) for 17 October 2003.

For a number of variables between six and eight, Duband (1981) proposes the following expression:

$d^{2}=\omega^{2} \sigma_{D}^{2} \Rightarrow d=\omega \sqrt{\frac{1}{f(x)} \sqrt{\frac{p(1-p)}{25}}}$

in which $\omega$ is a parameter that should be increased/decreased if the number of analogous situations are lower than 10 or more than 50 .

The "criterion of correlation" is applied to select those days that have high correlation coefficient with the test day. The correlation coefficient used is the linear Pearson's one and the values to calculate the correlation coefficient are $13 \mathrm{PC}$ : 6 from $1000 \mathrm{hPa}, 6$ from $850 \mathrm{hPa}$, and other one at $500 \mathrm{hPa}$ pressure levels. These fields have been selected after testing different levels and taking into account the main factors responsible of flood generation in Catalonia (GibergansBáguena et al., 1997; Gibergans-Báguena, 2001).

The vectors containing the values are:

$\left(Z_{i 1}^{850}, Z_{i 2}^{850}, \ldots, Z_{i 6}^{850}, Z_{i 1}^{1000}, Z_{i 2}^{1000}, \ldots, Z_{i 6}^{1000}, Z_{i 1}^{500}\right)$

for the day $i$
$\left(Z_{t 1}^{850}, Z_{t 2}^{850}, \ldots, Z_{t 6}^{850}, Z_{t 1}^{1000}, Z_{t 2}^{1000}, \ldots, Z_{t 6}^{1000}, Z_{t 1}^{500}\right)$

for the test day, $t$

Candidate days that satisfied the next conditions (Duband, 1981) are selected as analogous ones:

$u^{2}=\frac{d^{2}}{r^{2}}<6$ and $r^{2}>0.25$

It is had to pay attention to those days which have $r<0$, (antithesis analogous day). They must be refused previously.

The first step in the analogous selection is the application of the explained criteria above the FSW and a certain number of analogous days are selected. Afterwards, a second "criterion of correlation" is applied over the first step outputs, using the SSW. Days best correlated are considered the most similar to the test day.

To avoid the possibility of ignoring a similar day in the FSW but with low correlation and high $d$, the thresholds used in Eq. (7) can be relaxed in order to pick more days.

\subsection{The MM5 model}

The MM5 mesoscale model (Grell et al., 1994; Dudhia et al., 2004) is one of the most widely used models by the scientific community. This numerical model has been run for a $48 \mathrm{~h}$ simulation period starting on 16 October 2003 at 00:00 UTC. Three domains connected with two way nesting and having 54, 18, $6 \mathrm{~km}$ horizontal grid resolution and 23 vertical levels have been used. The outer domain (domain 1 ) is centred in the northeast of Spain at geographical coordinate $\left(39.0^{\circ} \mathrm{N}, 0.0^{\circ} \mathrm{E}\right)$. Initial and boundary conditions are obtained from the $2.5^{\circ}$ resolution NCEP analyses available at 00:00 and 12:00 UTC, which are improved using surface and upper-air observations (ADP, Automated Data Processing observations from the NCEP). Full physics is used and a Betts-Miller scheme (Betts and Miller, 1993) is applied to parameterise convection for the first domain, Kain-Fritsch scheme (Kain and Fritsch, 1993) for the second domain and whereas no convective parameterisation is present over the third domain. The convective parameterisation of the this domain is not critical in the study case. Instead of being characterised by a convective pattern, the most rainfall quantities were produced by warm-wet wind advection triggered by orography. These parameterisations and resolutions have been used with reasonable results in other similar extreme meteorological events in the West Mediterranean area, like the cases of November 2001 (Arreola et al., 2003), June 2000 (Mariani et al., 2005; Romero et al., 2005), September 2002 and November 2002 (Romero et al., 2005).

\section{Results}

The probability outputs calculated by the analogous methods correspond on 16 and 17 October 2003. All probability outputs have different thresholds (Table 1) in addition to the Maximum Expected Rainfall (MER) and Average Expected 

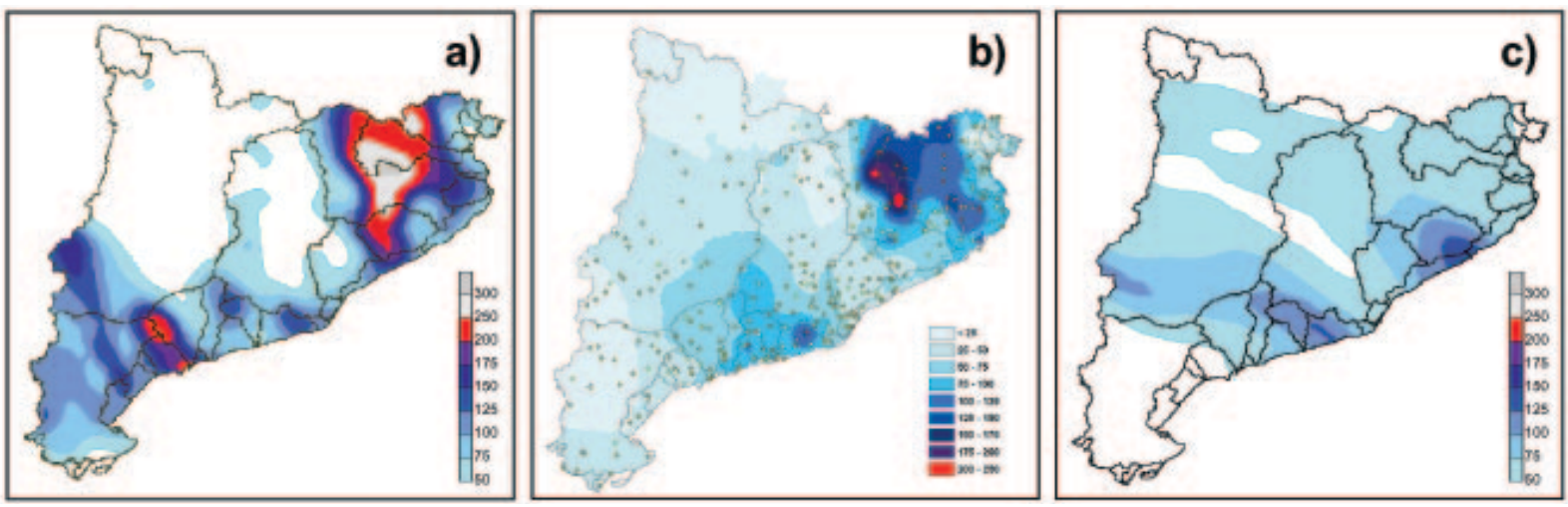

Fig. 5. Accumulated rainfall over Catalonia from 16 Ooctober 2003 at 00:00 UTC to 18 October 2003: (a) MM5 output for 6-km domain; (b) Observed from the rain gauge stations and (c) MM5 output for 6-km domain, without orography.

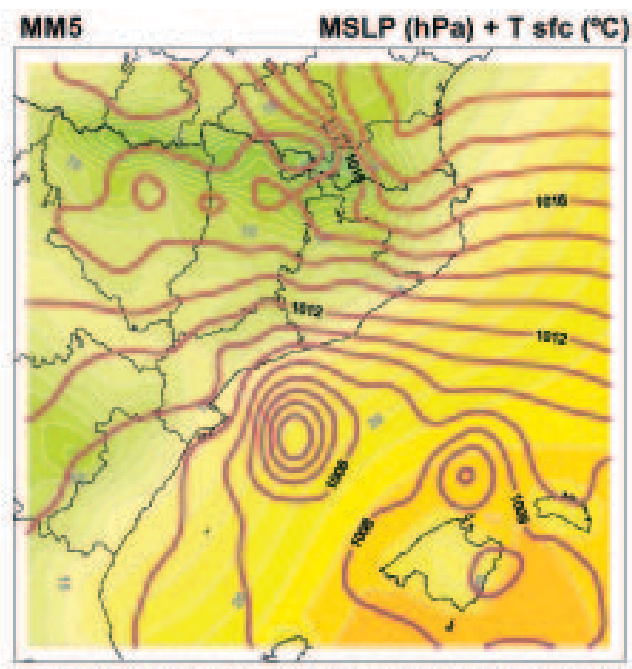

a) Initialization: 16 OCT 200302 / Forecast: 17 OCT 2003182

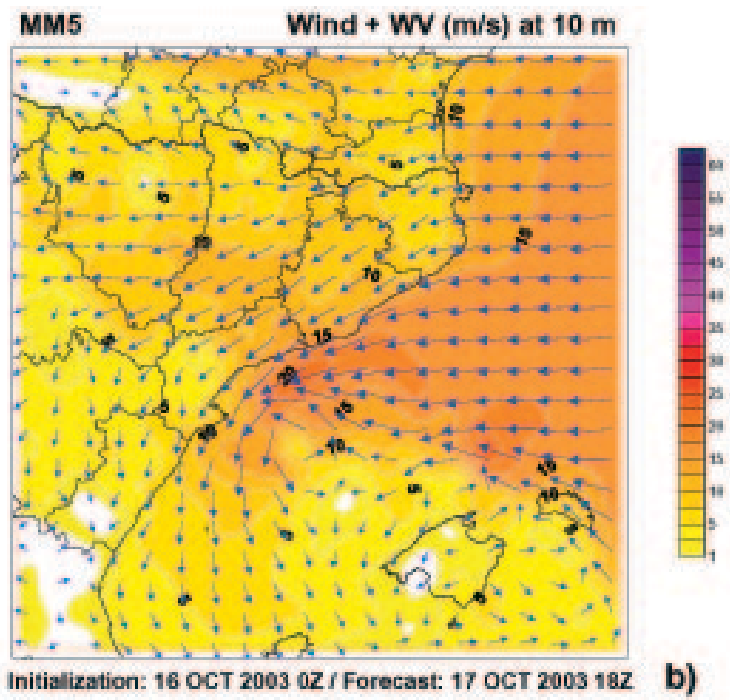

Fig. 6. MM5 outputs for the 6-km domain and for the 17 October 2003 at 12:00 UTC: (a) mean sea level pressure (red continuous lines) and surface temperature (shaded lines); (b) wind (arrows) and wind speed (shaded lines).

Rainfall (AER). The outputs have been calculated and represented over Catalonia using a $0.04^{\circ}$ grid resolution.

The probability of having a rainy day is over $95 \%$ in several Pre-Littoral places and in the East Pyrenees on both days. As the rain threshold goes up, the probability goes down. So, AER $>20 \mathrm{~mm} /$ day present probability values over $35 \%$ in the South and North Pre-littoral range on 16 October and around $30 \%$ on 17 October (Fig. 4) in the same areas. On the other hand, the accumulated AER between 1617 exceeds $40 \mathrm{~mm}$ at the North-East Catalonia. The model, as said above, also takes into account the MER, whose values over $200 \mathrm{~mm} /$ day are expected in North-East and near $200 \mathrm{~mm} /$ day in South Pre-littoral zone on 17 October.

In addition, the developed MM5 simulation appears to be strongly validated. For example, Fig. 5a shows the simulated precipitation in the $6 \mathrm{~km}$ resolution domain, quite similar to the records in Catalonia (Fig. 5b). As it can be seen in Fig. 5c, Pre-littoral range played a crucial role for the heavy rainfall production. Although in more detail, the accumulated precipitation and the covered area are overestimated.

The MM5 simulation also allows to analyse accurately the main meteorological features with a high spatial resolution. The evolution of the mean sea level pressure field for the 6$\mathrm{km}$ domain shows an interesting movement of a mesoscale low pressure centre firstly located at the Balearic Islands on 16 October at 00:00 UTC. This low was approached to the south Catalan coast in a first moment increasing the pressure gradient over the northern coast and the wind speed. Afterwards it moved to the Ebre Delta (S Catalonia) and returned to the Balearic Islands. There, the low pressure centre was deepening on 17 October at 12:00 UTC. From this position the low was approached to the Catalan coast again, with less than $1005 \mathrm{hPa}$ in its centre (17 October at 18:00 UTC, Fig. 6a) and producing wind speeds higher than $20 \mathrm{~m} / \mathrm{s}$ (Fig. 6b). Simultaneously, a second nucleus arisen at the North of Majorca Island on 17 October at 18:00 UTC, 

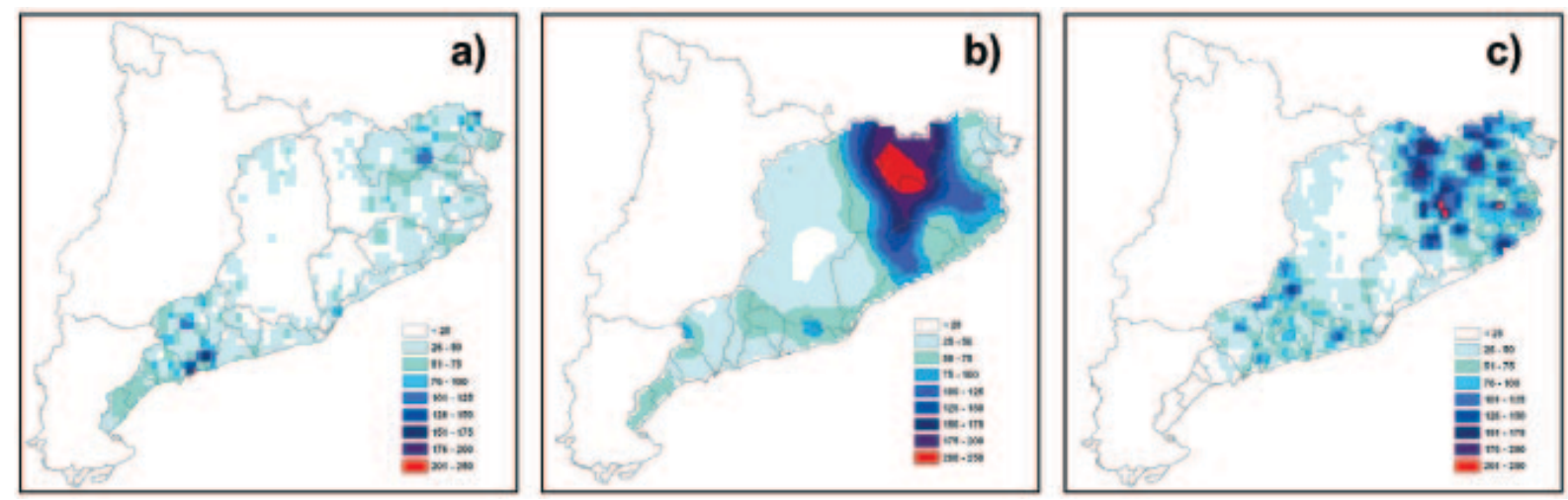

Fig. 7. Rainfall outputs for 17 October 2003 from 00:00 UTC to 24:00 UTC: (a) Maximum expected rainfall from the analogous technique; (b) Accumulated rainfall from the 6-km MM5 forecast and (c) Accumulated rainfall from SAIH (Automatic System of Hydrological Information) network.

followed the same way of the first low and facilitated the eastern wind flux continuation and reinforcement over the north Catalan coast. Afterwards, the two lows were moved to north Valencia coast (E Spain) and weakening. Despite this peculiar movement, described above, a great pressure gradient over northern coast was considerable all the time, being the responsible of the sea swell. On the other hand, the intense advection of moisture coming from the sea in addition to the orography forcing, was the responsible of the great precipitation amounts recorded on North-East region, where the mountains are situated perpendicularly to the wind flow.

\section{Comparison and conclusions}

With the MM5 outputs, in addition to the analogous method ones, and taking into account the event observations some conclusions appear clearly:

i) The first one is that both methods, probabilistic and deterministic, get good rainfall forecasts or probability distribution if they are compared with the observations (Fig. 7)

ii) The other one is that whereas the Analogous technique tends to underestimate the values on rainfall, the MM5 simulation tends to overestimate it (Fig. 7).

The Analogous method discriminates well rainy days with probability over $90 \%$ in a lot of pixels, specially near coast and North-East region. On the other hand, the AER field presents quite low values. That is because of some selected analogous days have very low amounts of precipitation registered. The ERP outputs, such as $\operatorname{ERP}(>10 \mathrm{~mm} /$ day $)$ and $\operatorname{ERP}(>20 \mathrm{~mm} /$ day $)$ on 17 October, show that the greatest precipitation probabilities above the thresholds are recorded in the zone where the maxima amounts of precipitation were finally observed.

Finally, it is observed the interest on applying both methods ensemble (deterministic and probabilistic). The MM5 provides an accurate evolution of interesting variables (rainfall, basically) and the analogous technique offers good outputs concerning rainfall probabilities and MER in compar- ison respect MM5 rainfall output. This process is found within the current research line of multiensemble prediction systems that is being developed within the INTERREG III-B AMPHORE project.

Acknowledgements. The authors thank the European INTERREG III-B AMPHORE project (2003-03-4.3-I-079) and the Spanish RAMSHES project (REN2002-04584-C04) for making possible the development of the present work.

Edited by: V. Kotroni and K. Lagouvardos

Reviewed by: anonymous referee

\section{References}

Arreola, J. L., Homar, V., Romero, R., Ramis, C., and Alonso, S.: Multiscale numerical study of the 10-12 November 2001 strong cyclogenesis event in the western Mediterranean, Proceedings of the 4th EGS Plinius Conference on Mediterranean Storms, Alcudia (Spain), 2-4 October 2002, CD-Rom, sec. 1, num. 30, 2003.

Barnolas Viladés, M.: Desarrollo de un sistema ACCESS/SIG en el ámbito de las ciencias de la atmósfera: Estudio de las inundaciones en Catalunya, 1901-2000. Trabajo para la obtención del Diploma de Estudios Avanzados (DEA). Programa de doctorado de Astronomía y Meteorología (Bienio 2002-2004), DAM/250201-05/0409, Internal publication, 2004.

Betts, A. K. and Miller, J.: A new convective adjustment scheme. Part II: Single column tests using GATE wave, BOMEX, ATEX and Arctic air-mass data sets, Q. J. R. Meteor. Soc., 112, 693709, 1986.

Bontron, G.: Prévision quantitative des précipitations: Adaptation probabiliste par recherche d'analogues. Utilisation des Réanalyses NCEP/NCAR et application aux précipitations du Sud-Est de la France, Institut National Polytechnique de Grenoble, Grenoble, 2004.

Del Hoyo, J., Fernández, A., Mestre, A., and Peral, C.: Sistema de predicción analógica de la precipitación del INM (PAP-INM), Servicio de Aplicaciones meteorológicas., Nota técnica no. 1. INM, Madrid, Spain, 2000

Diomede, T.: Uso degli analoghi meteorologici nella previsione operativa delle piene, Ph.D. thesis, Università degli Studi di 
Bologna Facoltà di Scienze Matematiche, Fisiche e Naturali Dipartimento di Scienze della Terra e Geologico-Ambientali, 2003.

Duband, D.: Reconnaissance dynamique de la forme des situations météorologiques, Application à la prévision quantitative des précipitations. Thèse de 3 cycle de la Faculté des Sciences de Paris, Paris, 1970.

Duband, D.: Reconnaissance dynamique de la forme des situations météorologiques. Application à la prévision quantitative des précipitations, Congrès de la Société Hydrotechnique de France, XIIIèmes journées de l'Hydraulique, Paris, France, 1974.

Duband, D.: Prévision spatiale des hauteurs de précipitations journalières, La Houille Blanche, 7/8, 1981.

Dudhia, J., Gill, D., Manning, K., Wang, W., and Bruyere, C.: PSU/NCAR Mesoscale modeling system. Tutorial Class Notes and User's Guide: MM5 Modeling System Version 3, www. mmm.ucar.edu/mm5/documents/tutorial-v3-notes.html, 2004.

Gibergans-Báguena, J., Llasat, M. C., and Rodríguez, J. Y.: Daily rainfall identification by using an analogous method over local thermodynamic data, Annales Geophysicae, European Geophysical Society, C237, 1997.

Gibergans-Báguena, J.: Métodos hidrometeorológicos aplicados a la predicción de precipitación diaria en Cataluña, University of Barcelona, Doctoral Thesis, Internal Publication, 2001.

Grell, G. A., Dudhia, J., and Stauffer, D. R.: A description of the fifth-generation Penn State/NCAR mesoscale model (MM5), NCAR Technical Note, NCAR/TN-398+STR, 1994.

Guilbaud, S.: Prévision quantitative des précipitations journalières par une methode statistico-dynamique de recherche d'analogues, Ph.D. Thesis, Institute National Polytechnique de Grenoble, Grenoble, 1997.

Kain, J. S. and Fritsch, J. M.: Convective parameterization for mesoscale models: The Kain-Fritsch scheme, in: The representation of cumulus convection in numerical models, edited by: Emanuel, K. A. and Raymond, D. J., Meteorological Monograph of the American Meteororological Society, 46, 165-170, 1993.

Llasat, M. C., Rigo, T., and Montes, J. M.: Orographic role in the temporal and spatial distribution of precipitation in flood events, Proceedings of the 1st EGS Plinius Conference on Mediterranean Storms, Maratea (Italy), 14-16 October 1999, 41-55, 1999.
Llasat, M. C., Rigo T., and Barriendos, M.: The "Montserrat-2000" flash flood event: a comparison with the floods that have occurred in the northeastern Iberian Peninsula since the 14th century, Int. J. Climatol., 23, 453-469, 2003.

Llasat, M. C.: La vulnérabilité en Catalogne et la perception sociale, La Houille Blanche, 6, 71-75, 2004a.

Llasat, M. C., Barnolas, M., Ceperuelo, M., Llasat, M., and Prat, M. A.: Algunos aspectos del impacto social de las inundaciones en Cataluña. Revista del Aficionado a la Meteorología, 20, www. meteored.com/ram/numero20/inundaciones.asp, 2004b.

Llasat, M. C., Barriendos, M., Barrera, A., and Rigo, T.: Floods in Catalonia (NE Spain) since the 14th century. Climatological and meteorological aspects from historical documentary sources and old instrumental records, J. Hydrol., in press, 2006.

Lorentz, E. N.: Atmospheric predictability revealed by naturally occurring analogues, J. Atmos. Sci., 26, 636-646, 1969.

Mariani, S., Casaioli, M., Accadia, C., Llasat, M. C., Pasi, F., Davolio, S., Elementi, M., Ficca, G., and Romero, R.: A limited area model intercomparison on the "Montserrat-2000" flashflood event using statistical and deterministic methods, Nat. Hazards Earth Syst. Sci., 5, 583-592, 2005.

Obled, C., Bontron, G., and Garçon, R.: Quantitative precipitation forecasts: A statistical adaptation of model outputs though an analogues sorting approach, Atmos. Res., 63, 303-324, 2003.

Ramis, C., Llasat, M. C., Genovés, A., and Jansà A.: The October1987 floods in Catalonia: Synoptic and mesoscale mechanisms, Meteorol. Applic., 1, 337-350, 1994.

Romero, R., Martín, A., Homar, V., Alonso, S., and Ramis C.: Predictability of prototype flash flood events in the Western Mediterranean under uncertainties of the precursor upper-level disturbance: the HYDROPTIMET case studies, Nat. Hazards Earth Syst. Sci., 5, 505-525, 2005.

Zampieri, M., Malguzzi, P. and Buzzi, A.: Sensitivity of quantitative precipitation forecasts to boundary layer parameterization: a flash flood case study in the Western Mediterranean, Nat. Hazards Earth Syst. Sci., 5, 603-612, 2005. 